\title{
EDUCAÇÃO AMBIENTAL NA EDUCAÇÃO BÁSICA: UM OLHAR PARA AS DIFICULDADES ENFRENTADAS POR PROFESSORES DE UMA ESCOLA PÚBLICA DE URUSSANGA (SC)
}

Camila Porto de Medeiros ${ }^{1}$

Viviane Kraieski de Assunção²

Resumo: Este artigo é resultado de uma pesquisa sobre as concepções e práticas de Educação Ambiental em uma escola pública em Urussanga (SC). A pesquisa incluiu entrevistas semiestruturadas com professores e a direção escolar, observação participante da rotina da escola e registros em diário de campo. A investigação permitiu conhecer os obstáculos para a efetivação da Educação Ambiental, a partir da perspectiva dos sujeitos da pesquisa. Constatou-se que os professores apresentam dificuldades em relacionar as disciplinas que lecionam com a temática ambiental, e apontam como fragilidades as deficiências na formação acadêmica, falta de formação continuada, más condições de trabalho e infraestrutura escolar.

Palavras-chave: Trabalho Docente; Rotina Escolar; Rede Pública de Ensino; Formação de Professores; Condições de Trabalho.

Abstract: This article is the result of a research on the conceptions and practices of Environmental Education in a public school in Urussanga (SC, Brazil). The research included semi-structured interviews with teachers and school directors, participant observation of the school's routine and field diary records. The investigation allowed to know the obstacles to the effectiveness of Environmental Education, from the perspective of the research subjects. It was found that teachers have difficulties in relating the subjects they teach with the environmental theme, and point out weaknesses in academic training, lack of continuing education, poor working conditions and school infrastructure.

Keywords: Teacher Work; School Routine; Public Education System; Teacher Training; Teachers Working Conditions.

${ }^{1}$ Universidade do Extremo Sul Catarinense. E-mail: camilaporto90@hotmail.com. Link para o Lattes: http://lattes.cnpq.br/2389148247661405

2 Universidade do Extremo Sul Catarinense. E-mail: vivianekraieski@gmail.com. Link para o Lattes: http://lattes.cnpq.br/3938314040854246

Revbea, São Paulo, v.16, № 1: 202-219, 2021. 


\section{Introdução}

O professor é, mais do que outros profissionais, "um intérprete por natureza" em função do seu ofício, porque "educar é ser mediador, tradutor de mundos" (CARVALHO, 2006, p. 77). Para Carvalho, o educador está no papel de alguém que pode despertar outras leituras da vida, novas reflexões e compreensões possíveis do mundo e sobre a ação de cada um na vida. A partir disso, os educandos podem repensar e reinterpretar as leituras sobre dado acontecimento, e isso vai ocorrer de acordo com as experiências, percepções, sentimentos e as relações sociais constituídas ao longo de sua trajetória da vida.

No tocante ao papel de professor como mediador de conteúdo, ele desempenha a função de educar sob muitas expectativas sociais, pois também contribui para a formação de visões de mundo e valores. Diante dessas demandas, muitas vezes, não são discutidas as circunstâncias e dificuldades enfrentadas por esses profissionais no cotidiano escolar.

Segundo Guimarães (2004), a fragilidade da prática pedagógica em Educação Ambiental passa por um conjunto de fatores que se somam, tais como a falta de formação específica, a falta de espaços de discussão sobre a sociedade e as questões ambientais, a falta de material didático e de produção acadêmica. Ou seja, isoladamente, estas questões e outras não explicam a fragilidade que ocorre nas escolas. Para o autor, a Educação Ambiental não pode mais continuar à margem da dinâmica social, dentro de uma perspectiva pouco crítica da realidade, uma vez que poderá resultar em posturas despolitizadas e conservadoras.

De acordo com Sato (2001a), a qualidade da educação ultrapassa o esforço em oferecer condições adequadas para a permanência dos alunos no ambiente escolar, porque também passa pelo aumento salarial do professor, pelo respeito pela sua profissão e dignidade das condições de trabalho.

Alinhado a essas reflexões, o presente estudo é resultado de uma pesquisa que tinha como objetivo analisar as percepções e práticas de Educação Ambiental em uma escola pública do município de Urussanga, sul do Estado de Santa Catarina. Ao ouvir os professores e observar a rotina escolar, compreendeu-se que fatores relacionados às condições do trabalho docente impactam as atividades junto à comunidade escolar e, consequentemente, afetam a abrangência e qualidade da Educação Ambiental na instituição. Neste artigo, abordamos os aspectos elencados pelos sujeitos da pesquisa como fragilidades que circundam o ensino e influenciam para a efetivação da Educação Ambiental coerente com a emancipação, a crítica e a transformação da realidade socioambiental. 


\section{Procedimentos metodológicos}

Esta pesquisa caracteriza-se como qualitativa em razão de buscar compreender os significados construídos pelos atores sociais, como estes criam o sentido do seu mundo e suas experiências (SILVA; GODOI; BANDEIRA-DE-MELLO, 2006). Do ponto de vista dos objetivos da pesquisa, o estudo possui caráter exploratório que visa favorecer maior familiaridade do pesquisador com o problema (GIL, 2002).

Como modalidade de pesquisa, escolheu-se o estudo de caso, uma modalidade holística, que tem como finalidade compreender uma determinada unidade social em próprios termos (GOLDENBERG, 2004). A pesquisa foi realizada em uma escola pública pertencente à rede estadual de educação básica do município de Urussanga, localizado no sul do Estado de Santa Catarina. No ano em que a pesquisa foi realizada, a escola contava com o total de 530 alunos matriculados nos ensinos fundamental e médio. O quadro de professores era composto de 45 professores nos três turnos do dia, entre professores efetivos e na categoria de Admissão em Caráter Temporário ACT. A escola possuía três funcionários contratados pela Associação de Pais e Professores, comumente denominados de serventes.

A pesquisa a campo consistiu, em um primeiro momento, em observar a rotina escolar dos alunos, professores e funcionários da escola. Para essa prática, determinou-se a técnica observação participante, em que o pesquisador, com autorização dos atores sociais envolvidos, integra-se ao grupo estudado, participando de suas atividades rotineiras (MARCONI; LAKATOS, 2003). A pesquisa de campo foi realizada em um período de cerca de quatro meses. Durante todo trabalho de campo, a pesquisadora realizou registros da observação participante em diário de campo (TRIVIÑOS, 1987).

Outro instrumento de pesquisa foi a entrevista semiestruturada, que consiste em elaborar um roteiro de questões previamente definidas pelo entrevistador (GIL, 2002). O público-alvo das entrevistas foi, inicialmente, a direção escolar e uma pedagoga responsáveis de forma direta pelo projeto escolar de Educação Ambiental, além de incluir um professor efetivo de cada disciplina das áreas de Ciências Humanas (Geografia, História, Filosofia e Sociologia), Ciências da Natureza (Física, Química e Biologia) e Matemática e das Linguagens (Língua Portuguesa, Língua Estrangeira e Educação Física). No total, foram realizadas 13 entrevistas individuais, que ocorreram nas dependências da instituição, gravadas com gravador de voz. Os nomes da escola e dos sujeitos da pesquisa não foram mencionados neste trabalho para preservar o anonimato.

Todo o processo de pesquisa atendeu aos preceitos éticos (BRASIL, 2012, 2016), com Certificado de Apresentação para Apreciação Ética (CAAE: 88020318.3.0000.0119). Os sujeitos entrevistados assinaram previamente o Termo de Consentimento Livre e Esclarecido (TCLE).

Os registros em diário de campo e as falas dos sujeitos entrevistados foram analisados por meio do método de interpretação de sentidos, que Revbea, São Paulo, v.16, № 1: 202-219, 2021. 
consiste nas fases de pré-análise, exploração do material, tratamento dos resultados e interpretação. O método propõe a leitura compreensiva dos dados para conhecer as particularidades e, posteriormente, explorar o material em direção daquilo que está implícito. Esta compreensão busca os sentidos atribuídos pelos participantes e, por fim, faz-se um diálogo entre essa interpretação e o referencial teórico (GOMES, 2010).

\section{Resultados e discussões}

\section{Os desafios da interdisciplinaridade e a formação docente}

As experiências de Educação Ambiental ao redor do mundo permitem concordar que uma única disciplina não é suficiente para desenvolver discussões a respeito das questões ambientais, uma vez que permeiam por diferentes áreas dos saberes (BRASIL, 1998). Cabe às redes de ensino incorporarem "[...] aos currículos e às propostas pedagógicas a abordagem de temas contemporâneos que afetam a vida humana em escala local, regional e global, preferencialmente de forma transversal e integradora" (MEC, 2017, p. 19).

Tratando-se da questão ambiental, "[...] isso é, o conjunto de temáticas relativas não só à proteção da vida selvagem no planeta, mas também à melhoria do meio ambiente e da qualidade de vida das comunidades [...]" (BRASIL, 1998, p. 176), ela aborda processos intensamente vividos pela sociedade. Implícita ou explicitamente, estas questões podem estar inseridas em muitas áreas do currículo escolar.

[...] a Literatura, a Geografia, a História e as Ciências Naturais sempre veiculam alguma concepção de ambiente, valorizam e desvalorizam determinadas ideias e ações, explicitam ou não questões, tratam de determinados conteúdos; e, nesse sentido, efetivam uma "certa" educação ambiental. A questão ambiental não é compatível apenas a partir das contribuições da Geografia. Necessita de conhecimentos históricos, das Ciências Naturais, da Sociologia, da Demografia, da Economia, entre outros (BRASIL, 1998, p. 27).

As entrevistas realizadas com professores permitiram evidenciar se eles estabelecem relações entre as disciplinas que ministram com a Educação Ambiental. Com exceção da professora de Filosofia, os profissionais demonstraram compreender interfaces entre as disciplinas e as questões ambientais (Quadro 1). 
Quadro 1: Falas dos professores sobre as relações das disciplinas que ministram com a Educação Ambiental.

\begin{tabular}{|c|c|}
\hline Disciplina & Fragmentos das falas dos professores \\
\hline $\begin{array}{l}\text { História e } \\
\text { Ensino } \\
\text { Religioso }\end{array}$ & $\begin{array}{l}\text { Sempre que é possível eu relaciono meio ambiente com o conteúdo. Tudo é } \\
\text { meio ambiente. Falei em leis com o } 8^{\circ} \text { ano e citei muito o meio ambiente, } \\
\text { especialmente de Urussanga, em relação ao direito e o cuidado com a } \\
\text { natureza, com o meio ambiente. }\end{array}$ \\
\hline Geografia & $\begin{array}{l}\text { A gente fala pouco em Educação Ambiental em si. Fala-se mais as palavras } \\
\text { preservação, sustentabilidade. Como a Geografia envolve " } n \text { " assuntos, tem } \\
\text { sempre a questão ambiental envolvida. Âs vezes, ela aparece com mais } \\
\text { clareza e às vezes ela está embutida em mais questões. }\end{array}$ \\
\hline $\begin{array}{l}\text { Língua } \\
\text { Portuguesa }\end{array}$ & $\begin{array}{l}\text { Com toda a certeza... [...] a gente está inserida no meio. Eu não posso } \\
\text { trabalhar uma disciplina isolada e esquecer do todo. Até porque eu trabalho } \\
\text { bem a questão da interdisciplinaridade. }\end{array}$ \\
\hline Arte & $\begin{array}{l}\text { Eu abordo Educação Ambiental quanto eu chego na Arte Contemporânea. } \\
\text { Quando eu falo do Museu ao ar livre Inhotim em Belo Horizonte (Instituto de } \\
\text { acervos de arte contemporânea e coleção botânica) porque tem a arte que } \\
\text { envolve a natureza. Então, a gente trabalha com a EA. Mais patrimonial daí } \\
\text { eu trabalho. Ambiental? Quando a gente trabalha com os pequenos, a gente } \\
\text { fala sobre meio ambiente, preservação, cultivo. Aí, trabalha reciclagem. }\end{array}$ \\
\hline Sociologia & $\begin{array}{l}\text { Nós temos alguns capítulos no livro didático de sociologia que tratam sobre } \\
\text { educação e meio ambiente. É onde a gente trabalha, principalmente, nos } \\
\text { terceiros anos médio a questão do meio ambiente. Em função da } \\
\text { problemática da sociedade capitalista, onde há a produção e o consumo em } \\
\text { massa e o desrespeito a natureza e o meio ambiente de maneira geral. }\end{array}$ \\
\hline Matemática & $\begin{array}{l}\text { Situações problemas na minha área. A gente discute, questiono eles em } \\
\text { relação à reciclagem, se Urussanga tem. Sobre os rios, não jogar papel no } \\
\text { chão da escola e em casa. Cuidar do meio ambiente. Mais no ensino } \\
\text { fundamental vem sobre a reciclagem no livro do } 7^{\circ} \text { ano [...]. Âs vezes, no } \\
\text { ensino médio, a gente trabalho educação financeira, porcentagem onde } \\
\text { trabalha muitas situações problemas, quanto por cento de poluição. Mas, não } \\
\text { assim especificamente no meu conteúdo. }\end{array}$ \\
\hline $\begin{array}{l}\text { Química e } \\
\text { Física }\end{array}$ & $\begin{array}{l}\text { Sim, bastante relacionado, principalmente, Química. Os elementos químicos } \\
\text { que se encontram na natureza. O que acontece com os materiais que a gente } \\
\text { joga no meio ambiente. O tempo de duração. }\end{array}$ \\
\hline Filosofia & $\begin{array}{l}\text { Acho que não [há relação]. Eu só sigo os conteúdos do documento } \\
\text { "Orientações curriculares" com foco em que ensinar. }\end{array}$ \\
\hline Inglês & $\begin{array}{l}\text { Tudo que a gente faz se procura estabelecer uma relação com uma ou outra } \\
\text { disciplina. Mas, há algumas coisas ficam mais difíceis conseguir relacionar. } \\
\text { Na minha disciplina a gente até pensou uma vez em trabalhar a respeito } \\
\text { disso. Foi em questão de vocabulário relacionado aos elementos da horta na } \\
\text { escola em razão do projeto com o fundamental. }\end{array}$ \\
\hline $\begin{array}{l}\text { Educação } \\
\text { Física }\end{array}$ & $\begin{array}{l}\text { Eu acredito que sim. Na verdade, a questão ambiental eu acho que engloba } \\
\text { tudo. Por mais que a minha prática não seja com relação a EA, querendo ou } \\
\text { não a gente está sempre naquela questão: preserve isso; vamos juntar o lixo. } \\
\text { Indiretamente, a gente faz alguma coisa. }\end{array}$ \\
\hline $\begin{array}{l}\text { Biologia e } \\
\text { Ciências }\end{array}$ & $\begin{array}{l}\text { No } 6^{\circ} \text { ano eu trabalho muito a questão ambiental a água e o lixo. Até faço } \\
\text { visita com eles no aterro sanitário no município. Como estou trabalhando a } \\
\text { questão de poluição do solo, aí entra na parte do lixo. E no final do conteúdo } \\
\text { eu levo eles na estação de tratamento de água porque no conteúdo eles } \\
\text { estudam as etapas de tratamento de água. }\end{array}$ \\
\hline
\end{tabular}

Fonte: Autoras (2020). 
Houve casos de professores que, apesar de procurarem relacionar o conteúdo da disciplina com as questões ambientais, encontravam dificuldades. Segundo eles, isso ocorria porque o currículo não trazia conteúdos relacionados ao meio ambiente e/ou à Educação Ambiental ou porque existia a mesma carência de assuntos nos materiais didáticos.

Nas falas desses professores, predominou como principal ponto em comum os conteúdos de cunho ecológico como preservação, natureza, poluição do solo e da água. Mas também foram citados outros temas, como sustentabilidade, consumo em massa, problemas da urbanização e legislação.

Alguns professores salientaram que o tema meio ambiente teria que ter caráter interdisciplinar. A seguinte fala é um exemplo:

O assunto deve ser interdisciplinar. Como tudo é meio ambiente envolve todas as disciplinas. Não só Física, Química, Biologia, Ciências. Todas as disciplinas podem ajudar um pouco o meio ambiente. Até mesmo a Matemática ajuda bastante.

O Projeto Político Pedagógico (PPP) da escola estudada prezava pela interdisciplinaridade, e os temas transversais eram os instrumentos para colocá-la em prática. Os temas na escola eram divididos por área de conhecimento, em razão da afinidade com os conteúdos. Esta circunstância foi expressa como uma preocupação por alguns professores. Uma professora, por exemplo, afirmou: "Assuntos fora da grade não dá para trabalhar, a não ser que você consiga casar com o assunto da grade que é um planejamento para um ano todo."

Para inserir os temas transversais nas aulas, os professores planejavam palestras com profissionais de diferentes áreas; saídas de campo em empresas, instituições, comunidades; as turmas realizavam trabalhos para serem expostos na escola e ações que ocorriam em disciplinas afins em razão do oferecimento de conteúdos semelhantes ou por meio de professores que lecionavam as mesmas disciplinas.

Durante a realização da pesquisa, o tema transversal Meio Ambiente ficou centrado nos anos iniciais do ensino fundamental. Apesar da maioria dos profissionais ter concordado que a Educação Ambiental fazia parte de diferentes formas nas suas disciplinas, também foi possível identificar trechos das suas falas que podem justificar as razões pelas quais o tema transversal isolou-se em algumas áreas de conhecimentos. As respostas abaixo fazem parte do questionamento a respeito das dificuldades para trabalharem a Educação Ambiental. 
[...] a falta de informação dos professores. Incluo a minha também, que falta um pouco de informação sobre o assunto. [Meio Ambiente] não é muito a minha área. É mais a área de Biologia. E eu peco nisso. Eu falar apenas o que eu tenho conhecimento, muito pouco. $E$ não abrange tanto quanto deveria. (Professor de História e Ensino Religioso)

Não é uma questão de não ter interesse. É que é mais específica para quem trabalha Geografia, Ciências, Sociologia, Biologia. Eu deixo mais para elas e aí eu fico acomodada. A partir do momento que eu tiver um pouco mais de interesse em um tema, por exemplo, daqui a pouco vai faltar água para nós, onde eu sei que vai faltar, eu tenho que estar consciente que eu tenho que trabalhar especificamente na minha disciplina. $O$ livro didático não traz e no currículo não tem. Não como tema transversal. (Professor de Matemática)

Eu tenho dificuldade de fazer a relação entre o conteúdo e um problema ou fazer uma atividade. Por exemplo, relacionar ao rio. E os materiais didáticas não contribuem. (Professor de Química e Física)

A minha disciplina é complicada. Por ser prática, existe uma resistência dos alunos. Para eu dar uma aula teórica e mais conversa é extremamente trabalhoso. $E$ até eles pararem para ouvir, já foi metade da aula. (Professor de Biologia e Ciências)

Em história, de repente, atualidade com os terceiros e o $9^{\circ}$ ano... A história do Brasil atual, por exemplo, e a mundial. De repente, trabalhar mais o meio ambiente neste setor. Para trabalhar o meio ambiente no passado, de repente uma professora de Ciências e Geografia. Eu sei mais sobre o meio ambiente atual, minhas leituras. (Professor de História)

Diante das afirmações expostas, entendeu-se, principalmente, que os professores entendiam que a Educação Ambiental deveria ser trabalhada dentro de uma visão disciplinar, seja como uma prática educativa integrante de disciplinas específicas ou somente relacionadas aos conteúdos de cunho ecológico.

Além da ausência do conhecimento teórico e de estratégias interdisciplinares e transversais da prática pedagógica, as visões dos profissionais poderiam estar vinculadas à forma histórica na qual foi organizado o conhecimento nas academias. Brugger (1994) explica que existem duas tendências. A perspectiva oferecida pelas Ciências Humanas é uma delas, em que os fatores histórico-sociais são mais relevantes, ausentando-se dos aspectos técnicos e naturais da questão ambiental. É uma tendência restrita ao ensino formal nos níveis de graduação e pós-graduação.

Segundo a mesma autora, há outras tendências que não podem ser 
ambientais já ocorre sob suas dimensões técnicas e naturais, predominando os temas ecológicos na educação para o meio ambiente (BRUGGER, 1994). Brugger salienta que o diálogo entre as Ciências Humanas e as Ciências Naturais e Exatas deverá fortalecer-se com as atuais discussões dos temas socioambientais, os quais não aceitam unicamente 0 conhecimento especializado.

Acrescenta-se também a afirmação de Leff (2002) de que o enfrentamento dos dilemas civilizatórios dependerá da capacidade dos indivíduos de perceberem os limites do conhecimento padrão cognitivista, centrado na análise, na fragmentação, na separação do sujeito do objeto e, ainda, na compartimentação disciplinar para planejar e gerir as problemáticas socioambientais.

Alguns professores ouvidos pela pesquisa ressaltaram a necessidade de uma formação específica em Educação Ambiental relacionada à sua área de formação ou interdisciplinar. Outros professores, apesar de afirmarem compreender que havia certa relação da Educação Ambiental com a disciplina ministrada, não consideravam que esta temática estava diretamente a sua área de formação inicial.

Essas afirmações nos levam a uma reflexão a respeito de uma formação continuada de docentes com foco ao meio ambiente. Para Sato (2001b, p. 8), alguns professores podem se perguntar "Como esse adjetivo transforma a educação? Ou, como muit@s indagam, há necessidade de outra educação?". De modo geral, a autora acentua que a educação tradicional negligencia muitos valores fundamentais, não respondendo às demandas socioambientais. Também fazem parte do problema, segundo Sato (2001b), os moldes tradicionais de ensino nas licenciaturas e bacharelados.

A Política Nacional de Educação Ambiental (PNEA), de 1999, traz diretrizes para serem aplicadas nos diferentes estágios de formação do professor, assim como a necessidade de formação complementar em sua área de atuação (BRASIL, 1999).

O Estado de Santa Catarina, por meio de diferentes documentos, tem orientado os gestores e os professores da educação básica para trabalharem novas demandas sociais, educacionais e curriculares nos últimos anos, a exemplo disso, existem os temas transversais, que mudam no decorrer das demandas.

Sobre a fragilidade em relação à carência de formação continuada, vale ressaltar as informações levantadas por Moraes e Loureiro (2017) a respeito dos investimentos em Educação Ambiental em Santa Catarina. Os autores revelaram que a Secretaria de Educação de Santa Catarina não investiu recursos na Educação Ambiental desde que esta dimensão da educação começou a fazer parte das Propostas Curriculares de Santa Catarina, ou seja, a partir de segunda versão em 2014. 
Ainda de acordo com os autores, os investimentos encontrados na área da Educação Ambiental correspondentes aos anos de 2013, 2014 e 2016 foram oriundos do Governo Federal e, dentre os repasses, em 2014 foram destinados recursos para o desenvolvimento de cursos de formação continuada para Diversidade, Educação Ambiental e marcos legais no currículo da educação básica (MORAES; LOUREIRO, 2017).

$\mathrm{Na}$ escola estudada não se obteve informação sobre a ocorrência desse curso mencionado ou algo similar, bem como de outras formações relacionadas à Educação Ambiental, fato demonstrado na fala de uma das professoras que lecionava há 11 anos na instituição: "Faltam cursos de capacitação em cada área específica ou para todas as disciplinas. E também não tivemos mais cursos de capacitação de modo geral".

Para concluir, Moraes e Loureiro (2017, p. 200) enxergam o repasse de recursos advindos exclusivamente do Ministério da Educação (MEC) como um ponto de vulnerabilidade, pois revela "[...] um cenário em que as políticas são construídas (de cima para baixo), numa lógica gerencial apaziguadora dos conflitos e de lutas por direitos". A última atualização em 2014 da Proposta Curricular de Santa Catarina (PCSC) evidenciava aspectos de influências do MEC; os repasses de investimentos à educação foram condicionados à adesão do estado às políticas federais que significam, na opinião dos mesmos autores, o enfraquecimento da participação das escolas do estado na construção de políticas baseadas na materialidade vivida por seus educadores.

Os dados trazidos por Moraes e Loureiro (2017) refletem sobre a situação da Educação Ambiental na escola lócus desta pesquisa. O estado de Santa Catarina tem exigido dos professores a introdução da Educação Ambiental como um dos temas transversais, porém não possibilitou condições de aperfeiçoamento para professores, deixando por conta destes o custeio da formação para tal. E este profissional, quando sentir a necessidade de aperfeiçoamento, tende a priorizar os cursos relacionados à sua área de formação específica devido ao plano de carreira, que impacta nos ganhos salariais. De modo geral, com exceção da professora de Língua Portuguesa, todos os professores possuíam pós-graduações lato sensu ou stricto sensu em suas áreas.

\section{Condições de trabalho docente}

Segundo os professores, a realização da formação continuada também encontra como empecilhos a falta de tempo e o excesso de trabalho. Essa realidade foi evidenciada na fala de uma professora: "A limitação é minha. Tentar ler mais... mas, na verdade, eu não tenho tempo, pois eu trabalho 60 horas. Não tenho nem tempo para ver televisão. Se a gente tivesse tempo para pesquisar na internet..."

No decorrer de 10 anos de experiência com grupos de formação continuada de professores-educadores ambientais em escolas públicas e privadas da Foz do Rio Itajaí (SC), Guerra e Figueiredo (2012) identificaram

Revbea, São Paulo, v.16, № 1: 202-219, 2021. 
que a falta de tempo, a instabilidade profissional e a baixa autoestima encontravam-se em meio a uma série de barreiras no processo de formação junto aos professores. Os autores alertaram que o mais grave é que esses motivos podem levar a sintomas de estresse profissional.

$\mathrm{Na}$ presente pesquisa, houve professores que falaram a respeito do assunto. Um deles relatou o seu ponto de vista sobre o seu principal obstáculo.

A falta do tempo. Porque o professor faz a atividade aqui na escola, dá aula. Em casa ele tem que preparar aulas novas, corrigir trabalhos e provas. E aí, ele tem uma vida em casa também, tem família. E aí falta o tempo para ele fazer as leituras necessárias para entender mais sobre o assunto. Ainda mais quando não é da disciplina dele.

Ferreira (2011) entrevistou professores dos anos finais do ensino fundamental da rede estadual de educação de São Paulo, SP. A sua pesquisa também apontou a falta de tempo e o excesso de trabalho como algumas das principais dificuldades encontradas pelos profissionais para realizarem cursos de formação continuada, tal como para planejar e dar continuidade a Educação Ambiental nessas escolas.

Os professores que, além de lecionar disciplinas, ocupam cargos que lidam com a burocracia e o atendimento de alunos, familiares destes e de professores, a exemplo da direção escolar e assessorias pedagógicas, compartilham desafios semelhantes em relação à sobrecarga de responsabilidades. Durante a pesquisa, a diretora da escola destacou como um dos desafios da função a grande burocracia para a organização de eventos, aquisição de recursos materiais, contratação de pessoal. As responsabilidades se estendiam a responder e-mails, ofícios, prestar contas ao financeiro, coordenar reuniões da associação de pais e professores, entre outras atividades.

As atividades administrativas ocupavam boa parte do tempo da diretora. Segundo ela, faltava-Ihe disposição para dedicar-se a atividades de escrita e leitura, as quais ela comentou que gostava de desempenhar. Escrever artigos e apresentá-los em eventos científicos, participar de seminários, concursos e competições da área educacional junto com os professores e alunos para divulgar os trabalhos desenvolvidos na escola eram algumas das metas da direção.

Para Souza (2003, p. 22), as políticas de reformas da educação contemporâneas têm confundindo a gestão escolar com a função de direção escolar, individualizando as "[...] responsabilidades da condução da escola na figura do diretor e colocando, na melhor das hipóteses, os órgãos colegiados de decisão - o conselho de escola - como institutos de controle da autoridade em que a fiscalização por parte das famílias é fundamental". Aparentemente, 
mesmo com o surgimento de propostas contemporâneas, estas não se centram em enxergar a escola em toda a sua complexidade como instituição que possui a sua própria cultura (SOUZA, 2003).

Oliveira (2004) comenta que a escola pública assume múltiplas funções e os professores têm de responder demandas que excedem a sua formação, sentindo-se obrigados a desempenhar funções de psicólogo, assistente social, enfermeiro e outras. De modo geral, tem-se colocado o professor como agente central das mudanças nos contextos de reformas educacionais, ou seja, como principal responsável pela escola, pelo desempenho do aluno e pelo sistema. Porém, ele se sente incomodado em tomar para si a responsabilidade pelo sucesso ou fracasso dos programas (OLIVEIRA, 2004).

A fala de uma professora expressa sua preocupação com a confusão que existe em relação à atuação do professor na escola, que acaba tirando o foco do profissional, que é de ensinar.

A questão da família que já está bem desestruturada e está sobrando tudo para a escola. A escola deixou de ser uma instituição onde ela passa o conhecimento. E, não que ela não tenha que ter este olhar de preocupação. Também é obrigação da escola, mas não é cem por cento obrigação dela. E ela está abraçando tudo isso, porque alguém deixou de fazer a tarefa em casa em um determinado momento e está sobrando tudo para nós aqui.

Este relato demonstra uma realidade que contribui para o sentimento de perda de identidade profissional (OLIVEIRA, 2004), em consequência dos variados papéis que os professores executam dada a carência de profissionais que atuam em áreas que a escola necessita.

Durante a pesquisa, assistiu-se à execução das multitarefas também das assessoras que atendiam o pedagógico. Segundo o PPP (2016) da escola, dentre as atribuições dos assessores, constavam: atender os alunos, orientar os professores quanto aos cronogramas, planejar e coordenação de reuniões pedagógicas, fazer cumprir regulamentos, preparar material de aula na ausência de professores ACT (Admissão de professores em Caráter Temporário).

No cotidiano da escola, comumente, chamava a atenção os momentos em que as assessoras apaziguaram conflitos entre alunos, alunos e professores, alunos e familiares. Em seguida, elas dirigiam-se para 0 cumprimento de tarefas administrativas, de planejamento e organização, exigindo mais uma porção de concentração. Observou-se que as assessoras não tinham horários fixos para o lanche por causa da alta demanda de trabalho, em especial, de atendimentos aos alunos relacionados às mais diversas situações de cunho escolar e/ou pessoal. 
Outra perspectiva sobre as condições de trabalho do docente diz respeito às políticas educacionais, que têm considerado a escola como uma "organização prestadora de serviços", concentrando-se em aumentar os índices de eficácia e eficiência com novas políticas, uma lógica que reduz muito a definição de escola diante da sua complexidade no contexto social (SOUZA, 2003).

A experiência de presenciar o cotidiano escolar, observar o trabalho dos professores e da administração, fez-se concordar com as afirmações de Oliveira (2004). Segundo a autora, há uma expectativa de que trabalho docente atenda novas demandas pedagógicas e administrativas, o que leva a um sentimento de insatisfação e insegurança dos professores, uma vez que se tem exigido do profissional domínio de práticas e novos saberes sem uma preparação adequada (OLIVEIRA, 2004).

\section{As limitações do currículo e da infraestrutura escolar}

Quanto ao currículo escolar, outro assunto recorrente de discussões entre os profissionais da educação, diferentes autores que discutem a implementação da Educação Ambiental, em especial, na Educação Básica, ressaltam que não faz sentido ela não estar integrada de forma plena ao currículo escolar (FERREIRA, 2011). Da mesma forma que deve fazer parte dos currículos de formação de professores, a Política Nacional de Educação Ambiental também deixa explícito, no seu art. 9으, que a EA deve ser integrada, contínua e permanente no âmbito escolar (BRASIL, 1999).

$A$ realidade escolar tem demonstrado contrariedades em relação às diretrizes normativas e à literatura (FERREIRA, 2011; CARVALHO, 2006; GUIMARÃES, 2004). Na maioria dos casos, a Educação Ambiental tem sido inserida por meio de atividades extracurriculares, afastando-a da sua intencionalidade de transcender a educação tradicional e contribuir para a formação crítica dos alunos frentes aos desafios socioambientais.

$\mathrm{Na}$ escola estudada, para compreender as limitações da inserção da Educação Ambiental ou temática ambiental, foram ouvidos os professores a respeito do assunto, o que permitiu-se identificar as principais circunstâncias limitadoras.

A primeira limitação seria a obrigação de passar todo o conteúdo programado até final de cada ano. Estava relacionada ao calendário escolar e à carga horária das disciplinas, os quais foram destacados como preocupações constantes pelos entrevistados.

A duração de cada aula correspondia a 45 minutos, fator apontado por alguns profissionais como limitador para propor atividades complexas ou que necessitavam não somente de um número maior de aulas para a finalização, como também de aulas faixas que proporcionassem trabalhar o conteúdo sem interrupções (intervalos entre as aulas) durante um período do dia: 
Quando a gente monta um projeto, a gente tenta inserir no que a gente está dando de aula. Nem sempre se encaixa porque os projetos de estendem. E tem limite para tudo. Infelizmente, você trabalha com nota e tem que pôr no sistema.

A terceira limitante remete à determinação legal contida na Lei de Diretrizes e Bases da educação (LDB), que traz a obrigatoriedade da escola e do professor planejarem períodos de recuperação de estudos para os alunos de menor rendimento, ou seja, aplicar novas avaliações para recuperar provas ou trabalhos que atingiram notas insuficientes que ocorrerá no decorrer do ano letivo ou ao final. Para o MEC, a LDB, ao trazer a obrigatoriedade recuperação de estudos contribui para romper com a "cultura de reprovação" (MEC, 2013).

$\mathrm{Na}$ perspectiva de alguns entrevistados, as avaliações extras contribuem para a desmotivação profissional, pois elas resultam em carga excessiva de trabalho e tempo para aplicá-las, comprometendo o andamento de demais atividades, bem como o desenvolvimento de novos planejamentos.

Outro problema é que nós temos que fazer as provas de recuperação a cada prova. Ocupa muito tempo e atrapalha o andamento de um trabalho mais complexo porque tem que apresentar resultados logo. E quando um trabalho se estende por muito tempo, neste meio tempo, o professor tem que postar notas. E estas notas acabam te segurando.

O atual estudo não teve a pretensão de julgar a referida normativa mencionada pelos professores, mas visou apresentar as principais dificuldades e limitações identificadas por eles, no intuito de compreender a organização e o planejamento do cotidiano da escola analisada, os quais podem interferir na implementação da Educação Ambiental.

Segundo Ferreira (2011), a organização escolar e o planejamento de ações são essenciais para o sucesso de uma atividade também interdisciplinar, por meio dos quais são definidos os objetivos, metas e reunindo pessoal e materiais.

Houve professores que comentaram que mesmo os conteúdos programáticos não são todos passados para a turma por razão do tempo de cada aula, ou seja, pelo número insuficiente de aulas. Esse cenário reflete o ensino tradicional conteudista, no qual o professor é o transmissor da cultura e do conteúdo. O conteudismo diz respeito ao processo de ensino que visa tornálo meramente uma transmissão de conteúdos historicamente produzidos. 0 sistema de avaliação é centrado na quantidade de informação que o aluno pode absorver no final de cada período letivo (LANGHI, NARDI, 2011). 
A precariedade da infraestrutura escolar foi outra limitação que se apresentou com frequência na fala dos docentes no decorrer do trabalho de campo, principalmente nos momentos de conversação na sala dos professores.

Um dos incômodos estava relacionado ao cumprimento das horasatividades na escola por motivo de não haver um espaço adequado na instituição, assim como não existia um computador para eles terem acesso ao diário on-line e outras atividades relacionadas às aulas. Durante a realização desta pesquisa, um computador foi recuperado para cumprir a função específica mencionada pelos professores. O laboratório de informática estava desativado por causa da infraestrutura que se encontrava comprometida. Nesse local também estava alocada a biblioteca. Os computadores eram obsoletos e outros equipamentos estavam aguardando manutenção. Essas mesmas situações aplicavam-se aos computadores destinados aos professores.

Tornava-se inviável os alunos trazerem os seus computadores para sala de aula, em razão do fato que não eram todos que poderiam trazer um aparelho individual. A escola temia quando à segurança desses aparelhos e dos professores. As salas também não possuíam tomadas suficientes para carregar os equipamentos eletrônicos e o sinal de Wi-Fi não alcançava todas as salas de aula.

Em meio à precariedade das instituições e dos equipamentos da escola, chamou a atenção a fala de uma professora: "Às vezes, falta papel higiênico na escola". Essas são questões que as escolas não possuem controle, pois dependem dos repasses de recursos financeiros do estado.

Um segundo professor também expôs o mesmo problema e sugeriu uma aplicação do recurso ao dizer que "Se a educação fosse prioridade no governo, materiais estariam disponíveis nas escolas para pesquisas. Equipamentos de laboratório. Trabalha-se só o local, em vez de trabalhar globalmente, podendo fazer. Este é o pior problema". Para ele, o repasse de recurso destinado para realizar viagens de estudos também poderia contribuir positivamente para o ensino, com o intuito de possibilitar que os alunos vivenciem contextos diferentes dos quais eles estavam acostumados a observarem no dia a dia.

Sato (2001a, p. 29) traz a reflexão de que "se a sociedade está em crise, a educação certamente estará". Significa pensar sobre as inversões de valores, as prioridades das políticas públicas, bem como pensar o próprio papel do professor.

Para responder algumas demandas da escola, durante a pesquisa in loco, frequentemente, observaram-se movimentos gerados pela direção, coordenadores, professores e familiares de alunos, no sentido de pensar estratégias para suprir necessidades básicas de ordem material na instituição. A organização de alguns eventos escolares tinha a finalidade de arrecadar fundos para consertar, revitalizar, trocar e comprar materiais, fazendo parte de 
muitas tentativas incansáveis para alcançarem metas a cada dificuldade que se apresentava.

A Lei de Diretrizes e Bases da Educação Nacional (LDB) determina a garantia de padrões mínimos de qualidade no ensino e acesso nas escolas ao estabelecer que sejam exercidas ações supletivas e redistributivas entre a União e os Estados para corrigir as disparidades (BRASIL, 1996). A atual escola possuía instalações construídas em meados do ano 1900. Além de possuir um caráter histórico, outros aspectos acabavam demonstrando a fragilidade da escola diante da má condição dos componentes básicos para a sua funcionalidade.

No ano anterior ao presente estudo, a região que se localizava a escola foi prejudicada com a passagem de um temporal que acabou danificando ainda mais os telhados da escola. Ocorreram infiltrações em muitas salas. Foi nesse episódio que a repartição da biblioteca foi comprometida, impossibilitando o reuso de livros, muitos destes tinham sido comprados com recursos da Associação de Pais e Professores (APP).

Para configurar a infraestrutura escolar, utiliza-se a definição mais comumente encontrada nas literaturas, obtida com base nos dados do Censo Escolar, como: local próprio de funcionamento da escola, água tratada, energia elétrica, saneamento básico (coleta de lixo, de esgoto e presença de banheiro), outros espaços e recursos escolares (biblioteca, laboratório, cantina, computadores e outros equipamentos eletrônicos) (ALVES; SOARES, 2013).

Diferentes estudos englobam outros itens básicos para a funcionalidade da escola, como: os espaços educacionais de apoio (salas administrativas), a acessibilidade, ambiente favorável para o ensino e aprendizagem (conforto térmico e acústico), a segurança e as necessidades de materiais para Atendimento Educacional Especializado (AEE) (ALVES; XAVIER, 2018).

Os itens de higiene, como sabonete, papel toalha e rolos de papel higiênico, devem ser incluídos nessas listas como componentes essenciais para uso diário, não apenas relacionado à presença ou não de banheiros. Também deve ser levado em conta que a escola funciona nos três períodos do dia, o que significa uma alta demanda desses recursos para os alunos, professores e funcionários.

Alves e Xavier (2018) destacam que muitas pesquisas têm tratado da infraestrutura escolar, e ressalvam que "[...] nas pesquisas em avaliação educacional, o foco não é a infraestrutura, mas sim a relação desse fator com o desempenho escolar, que é sempre direta no Brasil' (ALVES; XAVIER, 2018, p. 714). Segundo os autores, estudos com diferentes metodologias de análise evidenciaram relação entre a infraestrutura escolar e a qualidade educacional medido pelo Índice de Desenvolvimento da Educação Básica (Ideb). 


\section{Considerações finais}

A pesquisa apresentada neste artigo permitiu identificar as dificuldades enfrentadas por professores de uma escola de Educação Básica da rede pública para efetivar a Educação Ambiental em suas práticas pedagógicas. A partir da pesquisa de campo, surgiu a necessidade de evidenciar os problemas vivenciados por estes profissionais em suas rotinas de trabalho, que impactam a qualidade do processo de ensino e aprendizagem de forma mais abrangente. Centrar-se na perspectiva desses sujeitos permitiu argumentar que o cumprimento das diretrizes que norteiam a Educação Ambiental no país depende, dentre outros fatores, da valorização dos professores, do investimento em sua formação e da garantia de suas condições de trabalho.

\section{Agradecimentos}

Agradecemos à CAPES (Coordenação de Aperfeiçoamento de Pessoal de Nível Superior) pela taxa escolar que permitiu a realização dessa pesquisa.

\section{Referências}

ALVES, M.T.G.; XAVIER, F.P. Indicadores multidimensionais para avaliação da infraestrutura escolar: o ensino fundamental. Cadernos de Pesquisas, v. 48, n. 169, 708-746, jul./set. 2018.

ALVES, M.T.G.; SOARES, J.F. Contexto escolar e indicadores educacionais: condições desiguais para a efetivação de uma política de avaliação educacional. Educação e Pesquisa, São Paulo, v. 39, n. 1, p. 177-194, 2013.

BRASIL. Lei $n^{\circ}$ 9.394, de 20 de dezembro de 1996. "Estabelece as diretrizes e bases da educação nacional." Diário Oficial da União, Brasília-DF, 23 dez. 1996.

BRASIL. Secretaria de Educação Fundamental. Parâmetros curriculares nacionais: Meio ambiente e Saúde. Brasília. Brasília: MEC/SEF, v. 9, 1998.

BRASIL. Lei no 9.795, de 27 de abril de 1999. "Dispõe sobre a educação ambiental, institui a Política Nacional de Educação Ambiental e dá outras providências." Diário Oficial da União, Brasília-DF, 28 abr. 1999.

BRASIL. Conselho Nacional de Saúde. Resolução no. 466, de 12 de dezembro de 2012. Diário Oficial da União, Brasília- DF, 13. jun. 2013. Seção 1, p. 59. 2012.

BRASIL. Conselho Nacional de Saúde. Resolução no. 510, de 07 de abril de 2016. Diário Oficial da União, Brasília- DF, 24 mai. 2016. Seção 1, p. 44-46. 2016.

BRUGGER, P. Educação ou adestramento ambiental. Florianópolis: Letras Contemporâneas, 1994. 
CARVALHO, I.C.M. Educação Ambiental: a formação do sujeito ecológico. 2. ed. São Paulo: Cortez, 2006.

FERREIRA, C.E.A. O meio ambiente na prática de escolas públicas da rede estadual de São Paulo: intenções e possibilidades. Tese (Doutorado em Educação). Faculdade de Educação, Universidade de São Paulo. São Paulo, 2011.

GIL, A.C. Como elaborar projetos de pesquisa. São Paulo: Atlas, 2002.

GOLDENBERG, M. A arte de pesquisar: como fazer pesquisa qualitativa em ciências sociais. 8. ed. Rio de Janeiro: Record, 2004.

GOMES, R. Análise e interpretação de dados em pesquisa qualitativa. In: MINAYO, M. C. de S. (Org.). Pesquisa social: teoria, método e criatividade. 29 ed. Petrópolis, RJ: Vozes, 2010.

GUERRA, A.F.S.; FIGUEIREDO, M.L. Um panorama da pesquisa na formação continuada de professores educadores ambientais no Vale do Itajaí (SC): um olhar do Grupo de Pesquisa Educação, Estudos Ambientais e Sociedade GEEAS-UNIVALI. In: MENDONÇA, A.W.; SIQUEIRA, A.B.; MARCOMIN, F.E. (Orgs.)Educação, sociedade e meio ambiente no estado de Santa Catarina: múltiplas abordagens. São Leopoldo, RS: Oikos, 2012. p. 26-38.

GUIMARÃES, M. A formação de educadores ambientais. São Paulo: Papirus, 2004.

LANGHI, R.; NARDI, R. Interpretando reflexões de futuros professores de física sobre sua prática profissional durante a formação inicial: a busca pela construção da autonomia docente. Investigações em Ensino de Ciências, v. 16, n. 3, 403-424, 2011.

LEFF, E. Epistemologia ambiental. Tradução de Sandra Valenzuela. Revisão técnica de Paulo Freire Vieira. 2. ed. São Paulo: Cortez, 2002.

MARCONI, M.A.; LAKATOS, E.M. Fundamentos de metodologia científica. 5. ed. São Paulo: Atlas, 2003.

MEC. Ministério da Educação. Base Nacional Comum Curricular: educação é a base. Brasília: MEC, 2017. Disponível em: http://portal.mec.gov.br/index.php? option=com docman\&view=download\&alias $=79611$-anexo-texto-bncc-

aprovado-em-15-12-17-pdf\&category slug=dezembro-2017-pdf\&ltemid=30192. Acesso em: 10 dez. 2017.

MEC. Ministério da Educação. Estudos de recuperação. Conselho Nacional de Educação. 2013.2 Disponível em: $<$ http://portal.mec.gov.br/index.php?option=com docman\&view=download\&alia

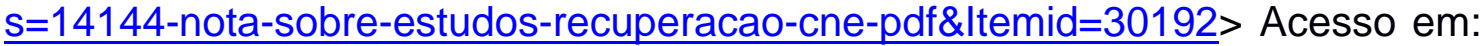
15 nov. 2018.

MORAES, A. L.; LOUREIRO, Carlos F. B. Políticas públicas de educação ambiental da secretaria estadual de educação de Santa Catarina: uma análise crítica. Ambiente \& Educação, v. 22, n.2, 2017.

Revbea, São Paulo, v.16, № 1: 202-219, 2021. 
SATO, M.T. Debatendo os desafios da educação ambiental. Revista Eletrônica do Mestrado em Educação Ambiental, Rio Grande, v. 1, n. FURG, p. R14-R33, 2001a.

SATO, M.T. Formação em Educação Ambiental: da escola à comunidade. In: Panorama da educação ambiental no ensino fundamental. Brasília: Ministério da Educação; Secretaria do Ensino Fundamental, 2001b. p. 07-15.

OLIVEIRA, D.A. A reestruturação do trabalho docente: precarização e flexibilização. Educação \& Sociedade, Campinas, vol. 25, n. 89, p. 1127-1144, set./dez. 2004.

SILVA, A.B.; GODOI, C.K.; BANDEIRA-DE-MELLO, R. Pesquisa qualitativa em estudos organizacionais: paradigmas, estratégias e métodos. 2 ed. São Paulo: Saraiva, 2016. 406 p.

SOUZA, A.R. Dentro e por Fora: A Cultura da Escola, a Política e a Gestão Financeira. Intermeio, Campo Grande, MS, v. 9, n. 17, 2003, p. 20-33.

TRIVIÑOS, A.N.S. Introdução à pesquisa em ciências sociais: a pesquisa qualitativa em educação. São Paulo: Atlas, 1987. 